Draft. Please cite the official version which appears in the handbook.

\title{
Reasons, Evidence, and Explanations
}

for The Oxford Handbook of Reasons and Normativity (ed. Daniel Star)

John Brunero, University of Nebraksa - Lincoln

It's commonly claimed that the normative reasons for something are the "considerations counting in favor" of it. The normative reasons for an action are the considerations counting in favor of that action. The normative reasons for believing that $\mathrm{P}$ are the considerations counting in favor of believing that P. And so forth. But it's just as commonly claimed that an appeal to reasons as "considerations counting in favor," by itself, won't give us what we need for an informative analysis of the concept of a reason. And some philosophers have been skeptical that any such informative analysis could be had. Consider, for instance, these passages from Scanlon and Parfit:

I will take the idea of a reason as primitive. Any attempt to explain what it is to be a reason for something seems to me to lead back to the same idea: a consideration that counts in favor of it. 'Counts in favor how?' one might ask. 'By providing a reason for it' seems to be the only answer. (Scanlon 1998:17)

It is hard to explain the concept of a reason, or what the phrase 'a reason' means. Facts give us reasons, we might say, when they count in favour of our having some attitude, or our acting in some way. But 'counts in favor of' means roughly 'gives a reason for'. Like some other fundamental concepts, such as those involved in our thought about time, consciousness, and possibility, the concept of a reason is indefinable in the sense that it cannot be helpfully explained merely by using words. (Parfit 2011:31) 
Other philosophers, however, have challenged this view, suggesting that we can provide an informative analysis.

Some have argued that we can understand reasons as evidence - specifically, as evidence of what you ought to do (or believe, or want, etc.). The reasons-as-evidence view, which has been defended in a series of papers by Stephen Kearns and Daniel Star (2008, 2009, 2011, 2013, 2013b), is committed to the following biconditional:

RAE Necessarily, a fact $X$ is a reason for an agent $\mathcal{N}$ to $F$ if and only if $X$ is evidence that $\mathcal{N}$ ought to $F$ (Kearns and Star 2008:37).

If RAE is true, it would allow us to present an informative analysis of the concept of a reason in terms of two other concepts on which we have some independent grasp: evidence and ought. ${ }^{1}$ Moreover, the analysis would be a unified one in that it extends to reasons for actions, intentions, desires, beliefs, and any other attitudes held for reasons, including admiration, love, and fear. (You can substitute "intend to $\phi$," "believe that P," and so forth, in for $F$ in RAE.)

Other philosophers argue that we can analyze the concept of a reason in terms of the concepts of explanation and ought. Stephen Toulmin, for instance, held that a reason for one to $F$ is an explanation of why one ought to $F$ (Toulmin 1950; discussed in Schroeder 2007:35-36). But this view has trouble with reasons that are outweighed. When a reason to $F$ is outweighed, it's not the case that one ought to $F$, and so there's no explanation of why one ought to $F$ (because in general there's an explanation of $\mathrm{P}$ only if P). ${ }^{2}$ Although Toulmin's view is unpromising, John Broome (2004, 2013) has advanced a

\footnotetext{
${ }^{1}$ Judith Jarvis Thomson (2008:146) also analyzes reasons to act as evidence of what one should do.

2 One might be tempted to go counterfactual: $(\mathrm{CF}) X$ is a reason for $\mathcal{N}$ to $F$ if and only if $X$ would explain why $\mathcal{N}$ ought to $F$ were there no greater reason for $\mathcal{N}$ not to $F$. Problems loom. Suppose David has a reason to fight Goliath (namely, it would be an impressive display of bravery) that's outweighed by a greater reason
} 
more sophisticated account of reasons in terms of the concepts of explanation and ought. And there are other ways to understand reasons as explanations. Some have understood reasons in terms of the concepts of explanation and value. Roughly, they hold that a reason for $\mathcal{N}$ to $F$ is an explanation of why $\mathcal{N}$ 's $F$-ing would be good in some respect and to some degree (Raz 1999:23; Finlay 2006:7-8, 2012). And neo-Humeans can understand reasons as explanations of how an action would promote an agent's desires to some extent (Schroeder 2007). ${ }^{3}$

All of these accounts are accounts of normative reasons - that is, the considerations counting in favor of something and the considerations counting against it (the "pros" and the "cons"). They are not accounts of explanatory reasons - that is, the explanations of why something non-normative is the case (e.g., "The reason the pipes burst is that the water froze"). Nor are they accounts of motivating reasons - that is, the reasons for which an agent acts, and which may figure into an explanation of an agent's actions (e.g., "The reason he turned the handle was that he wanted to shut off the water"). But the reasons-asexplanations strategy does promise to show what explanatory, motivating and normative reasons have in common: they are all explanations (Finlay 2012). Whereas explanatory and motivating reasons explain non-normative facts (why the pipes burst; why he turned the handle), normative reasons explain normative facts (why $\mathcal{N}$ ought to $F$ ) or, on another view, evaluative facts (why $\mathcal{N}$ s $F$-ing would be good in some respect and to some degree).

not to fight Goliath (namely, the significant threat Goliath poses to David's well-being). But were there no greater reason not to fight Goliath - that is, were Goliath not to pose a significant threat to David's wellbeing - then there would be no impressive display of bravery in fighting Goliath, and so, in that world, it's not the case that that it would be an impressive display of bravery explains why David ought to fight Goliath. It follows from CF that that it would be an impressive display of bravery is not a reason for David to fight Goliath. That's wrong. A successful counterfactual analysis would have to avoid such objections.

${ }^{3}$ Given limitations on space, I'll restrict my focus here to views that analyze reasons in terms of another normative concept, like ought or good, and so I'll set aside neo-Humean accounts of reasons. 
In this paper, I'll consider and evaluate the prospects for both reasons-as-evidence and reasons-as-explanations. Here's the roadmap. I'll begin by discussing $(\S 1)$ reasons-asevidence, outlining some of the many attractive features of the view. I'll then present the central challenges currently facing the view. In particular, I'll discuss an objection (§2) to RAE that purports to show that not all facts which are reasons for $\mathcal{N}$ to $F$ are also evidence $\mathcal{N}$ ought to $F$, and two objections $(\S 3, \S 4)$ that purport to show that not all facts which are evidence $\mathcal{N}$ ought to $F$ are also reasons for $\mathcal{N}$ to $F$. I'll then turn to reasons-asexplanations, considering versions in which the explanandum is $(\S 5)$ some fact about what one ought to do, and $(\S 6)$ some fact about value. I'll conclude $(\S 7)$ that neither reasons-asevidence nor reasons-as-explanations, at least in the formulations considered here, have given us sufficient grounds for countering the skepticism expressed in the passages from Scanlon and Parfit above.

\section{§1. Reasons as Evidence}

Any account of reasons must take into account that reasons can be outweighed. For instance, Alvin could have some reasons to go to Rojo's this afternoon (excellent coffee; interesting music) but greater reason not to go (he's late for an important meeting). As we saw above, Toulmin's view is unpromising since it cannot extend to outweighed reasons. But reasons-as-evidence doesn't face the same objection, since evidence can also be outweighed. For instance, Beth's testimony that she saw Carl jogging yesterday is some evidence that Carl was jogging yesterday, but this evidence could be outweighed by a medical report stating that Carl broke his leg three weeks ago, which is stronger evidence that Carl was not jogging yesterday. So, the reasons-as-evidence theorist has no trouble with Alvin: there is some evidence Alvin ought to go to Rojo's (excellent coffee; 
interesting music) and stronger evidence that Alvin ought not to go to Rojo's (he's late for an important meeting). Moreover, the reasons-as-evidence theorist can explain why reasons are capable of being outweighed: reasons just are evidence of what one ought to do, and evidence is capable of being outweighed. This is one advantage of the view.

Another advantage is that RAE offers a unified analysis of reasons, extending to reasons for actions, beliefs, and other attitudes. Consider reasons for belief. Suppose Dave reads in the paper that you can buy coffee at Rojo's. This is a reason for Dave to believe that you can buy coffee at Rojo's. According to RAE, it's evidence that Dave ought to believe you can buy coffee at Rojo's. It's also evidence for the non-normative proposition that you can buy coffee at Rojo's. But what RAE holds is that it's evidence for the normative proposition that Dave ought to believe you can buy coffee at Rojo's. If there are pragmatic reasons for belief - that is, reasons for belief grounded in the nonepistemic benefits of believing (e.g., believing in God makes you happy, believing you're handsome improves your confidence, etc.) - then these facts would be evidence that one ought to believe some proposition without being evidence for that proposition. (Kearns and Star 2009:216-219).

Another advantage is that a distinction often drawn with regard to reasons - a distinction between the reasons there are and the reasons one possesses - is also drawn with regard to evidence. (The undiscovered bloody knife is evidence of the crime, but it's not evidence the detectives yet have.) Let's consider a case where the distinction is drawn with regard to reasons: suppose Ellie believes the Chili Powder jar contains chili powder when in fact it contains ricin. There is a reason for Ellie not to empty the contents of the jar into the stew, but this isn't a reason she has. According to Kearns and Star, there is 
evidence she ought not empty the contents of the jar into the stew, but it's not evidence she has (2009: 234-235).

Additionally, reasons-as-evidence seems well suited to account for the weight of reasons. Talk of the weight of reasons is based upon a common analogy: reasons are like objects on a scale - specifically, a two-pan, beam-balance scale, like the one Lady Justice carries around - which each have a weight that contributes to determining the overall tilt of the scales. A physical object in one pan on Lady Justice's scales will have a weight such that, were there no objects in the other pan, it would make the scales tilt to its side. However, if there were objects in the other pan, and the combined weight of those objects were equal to or greater than the combined weight of the objects in the first pan, then the scales would equal out or tilt the other way. Reasons are supposed to be analogous to the objects in the pans, each having a weight. And, what, if anything, one ought to do is supposed to be analogous to the overall tilt of the scales - whether they tilt left, right, or equal out. There are some limitations to this analogy - for starters, the weight of reasons isn't always additive, and reasons are often incommensurable - but the analogy is nonetheless useful and widely employed (Broome 2004:36-38; 2013:52). However, one advantage of reasons-as-evidence is that it promises to offer us a more precise way to understand the weight of reasons: the weight of a reason to $F$ is given by the extent to which the reason to $F$ raises the probability that one ought to $F$. To see how this is so, we need to first consider the specific conception of evidence that Kearns and Star endorse. Although a reasons-as-evidence theorist could adopt any particular understanding of evidence $^{4}$, or remain neutral among them, Kearns and Star endorse a probability-raising

\footnotetext{
4 Although if the concept of evidence were itself analyzed in terms of reasons for belief, then also holding reasons-as-evidence would involve one in some circularity.
} 
conception of evidence, according to which evidence is that which raises the probability (Pr) of a hypothesis. On this conception of evidence, $e$ is evidence for $h$ just in case $\operatorname{Pr}(h \mid e)$ $>\operatorname{Pr} h .{ }^{5}$ If we apply this conception of evidence to RAE, we get

Pr-RAE Necessarily, a fact $X$ is a reason for an agent $\mathcal{N}$ to $F$ if and only if $\operatorname{Pr}(\mathcal{N}$ ought to $F \mid X)>\operatorname{Pr}(\mathcal{N}$ ought to $F)$.

With this particular conception of evidence in hand, Kearns and Star are able to understand the weight of a reason to $F$ in terms of the extent to which it raises the probability that one ought to $F$ (Kearns and Star 2008:44-45; 2009:231-232).

Kearns and Star note some additional advantages to the view. One attractive feature of reasons-as-evidence is that it explains why reasons play the role in deliberation that they do (2009:224-226). Suppose that Fred is deliberating about whether to accept Ginger's invitation to dance. In deliberating, Fred will weigh the pros and cons of accepting the invitation. But why does Fred appeal to reasons in his deliberations? The reasons-as-evidence theorist has a plausible explanation: In deliberating about whether to accept Ginger's invitation, Fred is deliberating about whether he ought to accept Ginger's invitation. In any deliberation about whether $\mathrm{P}$, one considers the evidence for and against P. And so Fred will consider the evidence for and against the proposition that he ought to accept Ginger's invitation. But, according to RAE, the facts which are evidence for and against this proposition just are the reasons for and against Fred's accepting Ginger's invitation. And that's why Fred appeals to these reasons in his deliberations. Thus, reason-as-evidence allows us to explain why one appeals to the pros and cons in deciding what to do.

\footnotetext{
${ }^{5}$ Objections to this conception of evidence can be found in Achinstein 2001, especially chapter 4.
} 
Kearns and Star also go on to note another, similar advantage: reasons-asevidence can explain why we appeal to reason to $F$ when we attempt to rationally persuade others (as opposed to merely cause them to believe) that they ought to $F$. After all, if reasons weren't evidence of what one ought to do, then why would we appeal to them in attempts to rationally persuade others? We don't normally appeal to non-evidential sources when we attempt to rationally persuade someone of some proposition, and not just bring it about that they believe it. Additionally, it seems as though anything that could play a role in rationally persuading someone that they ought to $F$ should count as a reason to $F$. It would be odd to think that it's possible for someone, using evidence, to persuade someone else that they ought to $F$ without providing them with any reasons to $F$ (Kearns and Star 2009:226-227). ${ }^{6}$

So far, we've seen that there are a number of advantages to reasons-as-evidence: it gives intuitively correct verdicts for the examples we've considered, it accounts for and explains the pro tanto character of reasons in terms of the pro tanto character of evidence, it accounts for the weight of reasons by employing a probability-raising conception of evidence, it explains the distinction between the being and having of reasons in terms of the distinction between the being and having of evidence, it offers a unified account of reasons for actions, beliefs, and non-epistemic attitudes, and it explains the role of reasons in both deliberation and rational persuasion. Much more could be said in favor of the view. ${ }^{7}$ But we've already seen enough advantages to see why the view has received the attention it has. Let's now turn to some of the challenges facing reasons-as-evidence.

\footnotetext{
${ }^{6}$ In $\S 3$, we'll consider a basis for challenging this claim. Jonathan Dancy (2004) distinguishes reasons from enablers. But enablers can play a role in deliberation and rational persuasion without themselves being reasons.

${ }^{7}$ See especially Kearns and Star 2008 and 2009.
} 


\section{§2. Reasons without Evidence: Counter-evidential Reasons}

Our first challenge to RAE aims to show that some fact could be a reason for $\mathcal{N}$ to $F$ without being evidence that $\mathcal{N}$ ought to $F$. It involves a case of what I'll call a "counterevidential reason" - that is, a case in which some fact is a reason for $\mathcal{N}$ to $F$, but is at the same time evidence $\mathcal{N}$ ought not to $F .^{8}$

Suppose you're going to the movies tonight with five friends, and it's up to you to pick the film. Everyone's meeting at the Garden Theatre at 9:00, and there are only two films playing at the theatre, neither one of which you know anything about: Film $A$ and Film B. These are the only two options. It's already been decided that you'll be seeing just one of these films - seeing none of them is not an option - and it's your job to pick which one. Your friend Harold strongly prefers to see Film B. You know nothing about this film, but you do know that whenever Harold strongly prefers to see a film, it's sure to be the case that everyone else, including you, will hate it. So, the fact that Harold strongly prefers seeing Film B gives you good evidence that you ought not choose that film this evening, and ought to choose Film A instead. But you nonetheless have a reason to choose Film $B$ - just one that is outweighed. For Harold's preferences - or, if you like, facts about his future enjoyments - count just as much as the preferences of you and your other friends; it's just that, taking everyone's preferences into account, you ought to choose to see something else instead. So, the fact that Harold prefers to see the film is a reason for you to choose that film, but at the same time, it's evidence that you ought not to choose it.

\footnotetext{
${ }^{8}$ For other examples like the one below, see Brunero 2009 and McKeever and Ridge 2012.
} 
How could a defender of RAE respond to this example? One strategy would be to deny that Harold's preference constitutes a reason to choose that film. After all, one might argue, not all preferences, or future enjoyments, constitute reasons. Some philosophers believe that were someone to very much enjoy, say, torturing kittens, his sadistic preference wouldn't constitute any reason - not even one that is massively outweighed - to torture kittens. However, Harold doesn't take pleasure in anything immoral, nor need it be the case that he takes pleasure in what's aesthetically bad. (We could just as easily set up the example so that he has excellent taste and wants to see some high-brow film, but yet his wanting to see it is evidence that everyone else will hate it, since we're all less refined than Harold and would enjoy something low-brow instead.) Nor need Harold's film preferences reflect an uncompromising stubbornness or insensitivity on his part. Maybe he communicates this preference to you without yet knowing who else will be in the group or what preferences they'll have. Or maybe he simply doesn't adjust his preferences in advance for he knows that it's your job to pick the film taking into account the preferences of all. So, it seems hard to maintain that Harold's case is on a par with the kitten torturer.

Instead, Kearns and Star would likely say that Harold's preference is a reason to choose Film B and evidence that you ought to choose Film B. They would maintain that Harold's preferring to see Film B is both evidence that you ought to choose it and (stronger) evidence that you ought to choose Film $A$ instead. But this might prove to be a cost to their view. It's not clear that some fact, in a particular context, can be both evidence that you ought to choose Film B and evidence that it's not the case that you ought to choose Film B (since it's evidence that you ought to choose Film $A$ instead). 
Draft. Please cite the official version which appears in the handbook.

Kearns and Star's probability-raising conception of evidence seems to disallow such a possibility. Since Film $A$ and Film $B$ are the only two options, and you must choose just one of them, the probabilities of "you ought to choose Film A" and "you ought to choose Film B" should add to one, so that whatever raises the probability that you ought to choose Film $A$ lowers the probability that you ought to choose Film B, and whatever raises the probability that you ought to choose Film $B$ lowers the probability that you ought to choose Film A. ${ }^{9}$ But on the reply being considered, Harold's preference is both evidence you ought to choose Film B and evidence you ought to choose Film A, and so, on the probability-raising conception of evidence, Harold's preference both raises the probability that you ought to choose Film $B$ and lowers the probability that you ought to choose Film $B$ (since it raises the probability you ought to choose Film A). But that's incoherent. Harold's preference either raises, or lowers, or keeps the same, the probability that you ought to choose Film B; it can't both raise and lower it at the same time. So, on the probability-raising conception of evidence, it can't come out that Harold's

\footnotetext{
${ }^{9}$ One might object that I'm simplifying here, since I'm ignoring the possibility that that you have merely sufficient reason to choose Film $A$ and merely sufficient reason to choose Film B, and so it's not the case that you ought to choose Film $A$ and not the case that you ought to choose Film B. On this objection, I should say instead that the probabilities of the truth of the following three propositions should add to one: (1) you ought to choose Film A; (2) you ought to choose Film B; (3) it's not the case that you ought to choose Film A and it's not the case that you ought to choose Film B. (Kearns and Star discuss a similar possibility at 2009:238, n.15). If that's right, we need to suppose - what seems plausible in our case - that the reason doesn't affect the probability of (3). Let's suppose at the start that there's some probability of (3) - say Pr (.01), just to pick a number. If some fact increases the probability you ought to choose Film $A$, but this fact doesn't make (3) any more or less probable, then the difference would have to be made up elsewhere: by decreasing the probability that you ought to choose Film B. For instance, the fact that Film $A$ is 3 hours shorter than Film B, which runs for 5 hours, doesn't in itself make (3) any more or less probable. This fact is a reason to see Film $A$, and so, by Pr-RAE, increases the probability that you ought to choose Film A. This increase in the probability that you ought to choose Film $A$, however, has to be offset by a decrease in the probability that you ought to choose Film B. So, in our case we have to suppose - what seems true anyway - that Harold's preference doesn't make a difference to the probability of (3). More precisely, we have to suppose that when Harold's preferring to see Film B increases the probability that you ought to choose Film $A$, it doesn't also decrease to the same extent the probability of (3), and so must decrease the probability that you ought to choose Film B.
} 
preference is both evidence for your choosing Film $B$ and evidence against your choosing Film B.

However, it wouldn't be incoherent to say that Harold's preference raises the probability you ought to choose Film B relative to some subset of the total body of evidence, although it lowers the probability you ought to choose Film $B$ relative to the total body of evidence (Kearns and Star 2009:232n.10). If our subset excludes the fact that Harold's preferences provide assurance that the movie will be terrible, his preference does raise the probability you ought to choose Film B relative to the subset. But relative to the total body of evidence, Harold's preference lowers the probability that you ought to select Film $B$. But perhaps it's enough, for Harold's preference to constitute a reason, that it raise the probability that you ought to choose Film B relative to some subset of the total body of evidence.

But one might worry that this lowers the bar too far - that there may be facts which raise the probability you ought to $F$ relative to the subset that intuitively aren't reasons to $F$. For instance, if we exclude from the subset the fact that Harold's preferences provide assurance that the movie will be terrible, then you would have a reason to defend Harold's taste in film when his reputation is publically challenged by your friends. After all, relative to this subset, there's no evidence of Harold's unreliability, and so the public challenge to Harold's reputation - which is entirely unjustified relative to this subset provides you with evidence that you ought to defend Harold's taste in film. Moreover, the reason to defend Harold's taste in film would be a weighty one, since, relative to the subset, the public challenge significantly raises the probability that you ought to defend 
Harold's taste in films. But of course you have no such reason to defend Harold's taste in films; your friends are surely right that Harold has terrible taste in films. ${ }^{10}$

In summary, the problem of counter-evidential reasons is that the defender of reasons-as-evidence seems forced to say that some fact, in a particular context, is both evidence for it being the case that one ought to $F$ and evidence against it being the case that one ought to $F$. And it's hard to see how it could be both, especially on a probabilityraising conception of evidence.

\section{§3. Evidence without Reasons: Enablers}

One can also challenge RAE in the other direction, by pointing to cases in which some fact is evidence that $\mathcal{N}$ ought to $F$ but not a reason for $\mathcal{N}$ to $F$. Jonathan Dancy helpfully distinguishes reasons from "enablers" - that is, conditions that enable some fact to be a reason, or enable some fact that is a reason to play a certain role in practical reasoning. Dancy gives the following example of a line of practical reasoning, where only the first premise is a reason, and the others play enabling roles:

1. I promised to do it.

2. My promise was not given under duress.

3. I am able to do it.

4. There is no greater reason not to do it. ${ }^{11}$

5. So I ought to do it. (Dancy 2004: 38)

The problem, however, is that RAE might blur the distinction between reasons and enablers, since the enablers, while not being reasons, often constitute evidence one ought to do something.

\footnotetext{
${ }^{10}$ For further discussion, see Brunero 2009:540-544; Kearns and Star 2013:80-83.

11 One might worry about reasoning from (4) to (5) since it's compatible with (4) that the reasons to do it and the reasons not to do it equal out, in which case one shouldn't conclude that one ought to do it. But we could add in

(4') The reasons to do it are greater than the reasons not to do it. to avoid this worry.
} 
For instance, suppose I'm in doubt about whether I can do what I've promised to do, and I come to learn (3): I am able to do it. Had I been unable to do it, given oughtimplies-can, it wouldn't be the case that I ought to do it. But, by ruling out this possibility, the probability that I ought to do it increases. However, my being able to do it isn't itself a reason to do it, but just some fact that enables the fact that I promised to do it to be a reason to do it. ${ }^{12}$

Now suppose we have (1) - (3) as part of our background information and we come to learn (4): there is no greater reason not to do it. This is very good evidence for (5). Not only does (4) raise the probability of (5), but it here allows you, in your reasoning, to conclude that you ought to do it, where you couldn't have concluded this before. But, as Dancy notes, (4) is not itself a reason to do it; the absence of greater "cons" is not itself something to be put within the "pro" column. So, (4) constitutes evidence that you ought to do it, but isn't a reason to do it. ${ }^{13}$

In summary, the problem of enablers is that reasons-as-evidence threatens to blur the distinction between reasons and enablers, since enablers are often evidence of what one ought to do.

\section{§4. Evidence without Reasons: Non-explanatory Evidence}

Another challenge to RAE concerns cases in which there's evidence that $\mathcal{N}$ ought to $F$, but that evidence appears not to play any role, not even a partial one, in the explanation of why $\mathcal{N}$ ought to $F$. Such cases involve what I call "non-explanatory evidence." (As you

\footnotetext{
12 This objection against RAE is made by Guy Fletcher (2013). In Fletcher's example (p. 419), we are asked to consider someone who is the only possible candidate to be a donor for an important bone marrow transplant. In finding out that he is a match, and so can donate bone marrow, he acquires evidence that he ought to donate. But the fact that he can donate isn't a reason to donate.

${ }^{13}$ For further discussion of this point, see Brunero 2009:544-545, and the reply in Kearns and Star 2013:84-86.
} 
might guess, this objection is at the heart of the debate between the reasons-as-evidence and reasons-as-explanations camps.) The objection is designed to show that not all evidence that $\mathcal{N}$ ought to $F$ is a reason for $\mathcal{N}$ to $F$.

John Broome presents the following example: suppose a reliable book states that you ought to eat cabbage. ${ }^{14}$ This is evidence that you ought to eat cabbage, but isn't a reason to eat cabbage. Rather, your reasons to eat cabbage are provided by those facts that explain why the book states what it does - for instance, the fact that cabbage contains sulforaphane, or is a low-calorie food, or some such fact or facts. But the fact that a reliable book says you ought to eat cabbage - which is non-explanatory evidence that you ought to eat cabbage - isn't a reason for you to eat cabbage.

Kearns and Star have at least a couple of strategies of reply available. One strategy would be to argue that this evidence is in fact explanatory (of what one ought to do), and so the example would be just as much a counterexample to Broome's own proposal as to their own. Another strategy - perhaps pursued in combination with the first - would be to argue that the book's advice is in fact a reason to eat cabbage, and so the example poses no threat to RAE (nor to Broome's proposal, if the first strategy succeeds). If one pursues the second strategy while resisting the first, one could argue that the cabbage example, while no threat to RAE, does threaten proposals, like those of Broome and Toulmin, which claim (very roughly) that all reasons are explanations of what one ought to do, since the advice of the reliable book would be a reason to eat cabbage, but not help explain why one ought to eat cabbage. I'll limit myself here to

\footnotetext{
14 For the exchange involving this example, see Kearns and Star 2008: 46-49, Broome 2008: 100-102, and Kearns and Star, 2013: 71-74.
} 
discussion of the second strategy, and not discuss the question of whether the evidence is also explanatory in this example. ${ }^{15}$ I'll just assume that it isn't.

So, is the fact that the reliable book says that you ought to eat cabbage a reason for you to eat cabbage? Our initial reactions might pull us in different directions. On the one hand, we might be inclined to think so. After all, this fact plays the role of a reason in ordinary deliberation. I need not know the complex chemical properties of cabbage, nor the way those chemical properties contribute to human well-being, in order to see that there's something to be said for eating it. The testimony of a reliable book is enough to go on. We often rely on the testimony of reliable advisors when deciding what to do, without knowing the basis for their advice.

On the other hand, we might be inclined to think not. If we keep in mind that we are here speaking of objective, normative reasons - God's list of the pros and cons, to borrow an apt expression from Mark Schroeder (2011:322) - it's not clear why we should think that the fact that the reliable book says that one ought to eat cabbage is a reason for one to eat cabbage. If God's list of the pros and cons already contains what are uncontroversially reasons to eat cabbage (the fact that cabbage contains sulforaphane, the fact that it's a low-calorie food, or similar facts), adding that a reliable book recommends eating cabbage seems to involve a form of double counting - although this need not be objectionable if we specify that the addition of this reason to God's list doesn't contribute

\footnotetext{
${ }^{15}$ For further discussion of this first question - that is, of whether the reliable book's advice also explains why one ought to eat cabbage - see the exchange in Analysis between McNaughton and Rawling 2011 and Kearns and Star 2011, where the challenge is presented of how, once you hold that this advice is also explanatory, you could establish a difference between the Divine Advice Theory, where God reliably reports independent truths about what one ought to do, and the Divine Command Theory, where God's commands explain the existence of these truths about what one ought to do.
} 
any further weight to the reasons already there ${ }^{16}$ - or at least a redundancy, since the list already specifies those reasons that are the basis for the book advising as it does.

So it seems as though initial thoughts pull us in opposite directions. In the remainder of this section, I'll argue that the problem of non-explanatory evidence is indeed a problem for reasons-as-evidence. I'll argue that there are other cases of nonexplanatory evidence where, unlike the case of Broome's book, the evidence is of no use in the deliberations of the agent who is the subject of the relevant ought-fact. In these cases, we don't have the same intuitive temptation that we have in the case of Broome's book toward thinking that the non-explanatory evidence is a reason. And these cases present just as much of a difficulty for reasons-as-evidence. I'll first introduce those cases, and then offer a diagnosis of why reasons-as-evidence runs into difficulty here.

Suppose that Doris Kearns Goodwin, a highly reliable presidential historian, writes that Lincoln had conclusive reason to refrain from eating cabbage. She doesn't say anything more than this, and so we're in the dark about what the reason is. (Was he allergic to it? Or unable to digest it?) We do know that there was at least one reason for Lincoln not to eat cabbage, and that the combined weight of the reasons not to do so was greater than the combined weight of the reasons to do so, but we don't yet know what the reason(s) are. Given that Doris Kearns Goodwin is an expert on all things Lincoln, her writing that Lincoln had conclusive reason to refrain from eating cabbage is excellent evidence that Lincoln ought to have refrained from eating cabbage. However, according to RAE, if $X$ is evidence that $\mathcal{N}$ ought to $F$, then $X$ is a reason for $\mathcal{N}$ to $F$. And so it follows that her writing that Lincoln had conclusive reason to refrain from eating cabbage is a

16 See Garrett Cullity's "Weighing Reasons," especially $§ 1$, in this volume, for a discussion of why the addition of such reasons need not involve the addition of weight. 
reason for Lincoln to have refrained from eating cabbage. But that seems counterintuitive. Neither that she wrote this, nor what she wrote, is itself a reason for Lincoln to have refrained from eating cabbage. As we said above, we're still in the dark about what the reason is.

Consider another example. Suppose reliable Iris says to you that Janice has a very good reason to leave her husband Karl, but doesn't say anything more than this. That's evidence that there is a reason for Janice to leave Karl, and that the reason is a weighty one. But we don't know what that reason is. (Did Karl have an affair? Something worse?) However, note that Iris's saying to you that Janice has a very good reason to leave Karl is evidence that Janice ought to leave Karl. (It would certainly count as evidence on the probability-raising conception of evidence, since Iris's testimony raises the probability that Janice ought to leave Karl.) According to RAE, if $X$ is evidence that $\mathcal{N}$ ought to $F$, then $X$ is a reason for $\mathcal{N}$ to $F$. And so Iris's telling you that Janice has good reason to leave Karl is a reason for Janice to leave Karl. But, intuitively, Iris's testimony isn't itself, and nor does it convey, a reason for Janice to leave Karl. We're all still in the dark about what the reason is.

Note how these examples differ from Broome's book. In Broome's book, unlike my two examples above, the evidence that $\mathcal{N}$ ought to $F$ is evidence that's of use to $\mathcal{N}$ in $\mathcal{N}$ 's deliberation. The book which says that you ought to eat cabbage is giving you advice you can use in your deliberations. (It would be like the case where Iris is providing testimony to Janice, not us, and Janice has amnesia and so finds the testimony that she has a very good reason to leave Karl to be useful, since she doesn't recall the reason.) In Broome's book, the evidence is useful in the deliberations of the agent who is the subject of the relevant ought-fact. And, as we saw above, this yields an intuitive temptation to count it 
as a reason. But in our two examples, it's not the case that the evidence is useful in the deliberations of the agents (Janice and Lincoln) who are the subjects of the relevant ought-facts, and so there is no similar temptation to count them as reasons. But these two examples still pose a difficulty for reasons-as-evidence.

I'll now offer a diagnosis of why these two examples present a difficulty for reasons-as-evidence. The problem is that RAE threatens to blur a straightforward distinction between reasons and facts about reasons. I'll first explain the distinction, and then explain why RAE threatens to blur it. Reasons are those facts (or propositions or states of affairs, etc.) that stand in a relation to an action or attitude - specifically, the counting-infavor-of relation to an action or attitude. For instance, when we say that the pleasant weather is a reason for you to take a walk, we are saying that the fact that the weather is pleasant stands in the counting-in-favor-of relation to your taking a walk. But facts about reasons - e.g., that there are seven reasons for you to take a walk, that some of these reasons are shared by everyone, that none of them are particularly weighty - are not themselves reasons; they do not themselves stand in the counting-in-favor-of relation to that action or attitude. ${ }^{17}$ Just as you can distinguish your children - those creatures which stand in the is-a-child-of relation to you - from facts about your children (how many you have; how tall they are), you can distinguish reasons - those facts which stand in the counting-in-favor-of relation - from facts about reasons.

However, this is a distinction that RAE threatens to blur. According to RAE, necessarily, if $X$ is evidence that $\mathcal{N}$ ought to $F$, then $X$ is a reason for $\mathcal{N}$ to $F$. But a report about some fact about reasons could be evidence that $\mathcal{N}$ ought to $F$, and so such reports

\footnotetext{
17 These facts about reasons don't stand in the counting-in-favor-of relation to your taking a walk. They may stand in the counting-in-favor-of relation to other attitudes.
} 
would themselves have to be counted as reasons for $\mathcal{N}$ to $F$. In our first example, the presidential historian's testimony that Lincoln had conclusive reason to refrain from eating cabbage - testimony regarding a fact about (the existence of) a reason - was excellent evidence that Lincoln ought to have refrained from eating cabbage, and so had to itself count as a reason for Lincoln to have refrained from eating cabbage. But that's not plausible. Neither that the historian said this, nor what she said, is itself a reason for Lincoln to have refrained from eating cabbage. In our second example, Iris's telling you about the existence of a weighty reason for Janice to leave Karl is evidence that Janice ought to leave Karl, and so must itself, by RAE, count as a reason for Janice to leave Karl. But neither her telling you this, nor what she told you, is a reason for Janice to leave Karl.

In light of these examples of non-explanatory evidence, I think we have good grounds for rejecting RAE. But what about the case of Broome's book, in which I conceded that there is at least some intuitive support for thinking that the book's advice is a reason to eat cabbage, given its useful role in the agent's deliberations? Given the relevant similarities, I think we should treat Broome's book along the same lines of my other two examples. The book informs us of a fact about reasons - namely, that that we have a weighty reason to eat cabbage - and provides evidence that we ought to eat cabbage, but the book's advice isn't itself a reason to eat cabbage. It's perfectly compatible with this to allow that a good deliberator would take into account testimony about the existence of reasons to eat cabbage and act in light of this. And it's also perfectly compatible with this to allow that when one does eat cabbage for the reason that the book so advised, that fact that the book so advised is one's motivating reason. But the book's advising you to eat cabbage isn't itself a normative reason to eat cabbage. 
In summary, the problem of non-explanatory evidence is that there could be evidence that $\mathcal{N}$ ought to $F$ that doesn't help explain why $\mathcal{N}$ ought to $F$ (as in the examples of Janice and Lincoln), and it doesn't seem correct to allow that such evidence constitutes a reason for $\mathcal{N}$ to $F$. If one finds this line of objection to reasons-as-evidence persuasive, one might instead look toward analyses of normative reasons in terms of explanations, instead of evidence. To such views we now turn.

\section{§5. Reasons as Explanations of Oughts}

As we noted in the introduction, it wouldn't be correct to say that some fact is a reason for one to $F$ only if that fact explains why one ought to $F$, since when reasons to $F$ are outweighed, it's not the case that one ought to $F$, and hence there is no explanation of why one ought to $F$. This observation leads John Broome to propose a disjunctive reasonsas-explanations account: a reason to $F$ is either a fact that explains why one ought to $F$ (what Broome terms a "pro toto reason" - or, in earlier work, a "perfect reason") or a fact that plays a for- $F$ role in a "weighing explanation" where the explanandum could be, for instance, that one ought not to $F$ (what Broome terms a "pro tanto reason"). Let's consider Broome's views about each of these kinds of normative reason.

\section{$\S 5.1$ Pro Toto Reasons}

Pro toto reasons are defined as follows: "A pro toto reason for $\mathcal{N}$ to $F$ is an explanation of why $\mathcal{N}$ ought to $F^{\prime \prime}$ (Broome 2013:50). Importantly, pro toto reasons are not merely explanatory reasons, but are also one kind of normative reason. Broome writes:

We slide from ' $X$ is the reason why you ought to $F$ ' to ' $X$ is the reason for you to $F$, meaning exactly the same thing by it. The 'reason why' (meaning explanation) 
bumps into the normative 'ought', yielding a normative sense of 'a reason' that combines the meaning of both. (Broome 2013:50)

However, one might worry about Broome's account here. As I'll argue below, it doesn't seem as though every fact that explains why one ought to $F$ should count as a normative reason to $F$. (If I'm right, we can of course still call such explanations "pro toto reasons" but we shouldn't think, as Broome does, that pro toto reasons are one kind of normative reason.)

Let's suppose that Alvin ought to go to Rojo's and there are a couple of reasons for him to go (they have excellent coffee and interesting music) and no reasons not to go. In this case, it might appear that we can say that the fact that Rojo's has excellent coffee is a pro toto reason, since it explains why Alvin ought to go to Rojo's. (Or perhaps we could say that the conjunctive fact that they have excellent coffee and interesting music explains why Alvin ought to go.) But do either of these suggestions really explain why Alvin ought to go to Rojo's? After all, Rojo's could have excellent coffee and interesting music without it being the case that Alvin ought to go to Rojo's: think of the case where Alvin is running late for the important appointment. So, we might think that the explanation of why Alvin ought to go to Rojo's should be something like: Rojo's has excellent coffee and interesting music and there are no reasons of equal or greater weight for him not to go. However, while Rojo's having excellent coffee is a good candidate for being a normative reason for Alvin to go to Rojo's, Rojo's having excellent coffee and Rojo's having interesting music and Alvin having no reasons of equal or greater weight not to go - which perhaps does explain why Alvin ought to go - doesn't strike us as itself being a normative reason for Alvin to go. We would do better to say that the first two conjuncts are each normative reasons and the third is a fact about the absence of reasons not to go. 
However, Broome does note the familiar point that what counts as the explanation of some fact depends upon background knowledge and interests. He provides an example. Suppose Joanne broke a slate, and the roof leaks when it rains. What explains why the carpet is wet? Someone might say the explanation is that it rained. Someone else might say the explanation is that Joanne broke a slate. Someone else might say it's that the roof leaks. Although each claims to be presenting "the" explanation, these claims don't seems to be incompatible. Broome has a suggestion for why this is so:

I suggest we think there is really one big explanation of why the carpet is wet. It is a complex fact that includes as parts all the separate facts the three of us described. Each of us is picking out a part to stand in for the whole. We call it the explanation because it is standing in for the one big explanation. ... Which part we pick out will depend on our context: our background knowledge, our interests in the matter and so on. (Broome 2013:49)

We could apply this general lesson about explanation to our particular example: in some contexts, given our background knowledge and interests, it suffices to point to the excellent coffee and interesting music at Rojo's. But in other contexts, one might have to also point to the absence of reasons on the other side.

However, Broome's suggestion doesn't suffice to resolve our concerns, since sometimes neither the "part", nor the "big explanation" for which the part stands, will itself be a normative reason. If our background knowledge includes the fact that Alvin has two reasons to go to Rojo's (the excellent coffee, the interesting music), and we're asking for what explains why he ought to go to Rojo's, it seems right to say: "There is no consideration of equal or greater weight for Alvin not to go." This "part" stands in for a 
"big explanation" which includes: the fact that Alvin has two reasons to go to Rojo's, that these reasons are the excellent coffee and interesting music, that these considerations aren't here subject to undercutting defeat, that there are no reasons of equal or greater weight for him not to go, and perhaps more. But the "part" here is a fact about the absence of greater or equal reasons, not itself a normative reason, and the "big explanation" is a story which includes mention of (two) normative reasons, but isn't itself a normative reason. So, it may be incorrect to think that pro toto reasons - that is, explanations of why one ought to $F$ - are always themselves normative reasons.

\section{§5.2 Pro Tanto Reasons}

Let's consider the second kind of normative reasons: pro tanto reasons. Broome offers the following definition:

Definition: a pro tanto reason for $\mathcal{N}$ to $F$ is something that plays the for- $F$ role in a weighing explanation of why $\mathcal{N}$ ought to $F$, or in a weighing explanation of why $\mathcal{N}$ ought not to $F$, or in a weighing explanation of why it is not the case that $\mathcal{N}$ ought to $F$ and not the case that $\mathcal{N}$ ought not to $F$ [say, because the reasons equal out or are incommensurable]. (Broome 2013:53. See also Broome 2004:39)

A weighing explanation is understood in terms of the (admittedly imperfect) analogy to Lady Justice's scales. Just as we appeal to the objects in each of the pans, and their combined weights, to explain the tilt (if any) of the scales, we appeal to the pros and cons, and their combined weights, to explain the overall judgment of what one ought to do.

At this point, one might object to Broome's defining pro tanto reasons in terms of their role in explanations. After all, don't I appeal to reasons when I don't yet know what I ought to do, and so I'm not yet in the business of explaining why I ought to do some 
particular thing? In other words, aren't reasons relevant to deliberation, as well as explanation? (See Kearns and Star 2008:41.) However, Broome does tell us that epistemological talk of explanation could be equivalently put in metaphysical terms specifically, in terms of the making-it-the-case relation. He writes: "By 'explain' I mean the inverse of 'because,' so ' $A$ explains $B$ ' means the same as ' $B$ is so because $A$ is so.' We may also say, equivalently, 'A makes it the case that B." (Broome 2008:100). So, we could take Broome's claim that a pro tanto reason to $F$ plays the for- $F$ role in a weighing explanation of why, say, one ought not to $F$, to be equivalent to the claim that a pro tanto reason to $F$ plays the for- $F$ role in making it the case that one ought not to $F$. With that in mind, pro tanto reasons can be relevant to both the "backward-looking" context of explanation and the "forward-looking" context of deliberation. ${ }^{18}$

But one might wonder whether Broome has succeeded in providing us with an informative analysis of reasons. Broome tells us that pro tanto reasons play a "for- $F$ " role. But is this any more informative than saying that reasons are the "considerations counting in favor"? One might hear echoes of Scanlon ("Plays a for- $F$ role, how?' one might ask. 'By providing a reason for it" seems to be the only answer,") or of Parfit ("But 'plays a for- $F$ role' means roughly 'is a reason for one to $F$, ') in reaction to this proposal. Understanding reasons merely as considerations playing a for- $F$ role isn't informative (Kearns and Star 2008:43-43; Brunero 2013:814). But, fortunately, Broome doesn't understand reasons merely as considerations playing a for- $F$ role. On his view, reasons play a for-F role in making it the case that one ought to $F$ (or that one ought not to $F$, or that one neither ought to $F$ nor ought not to $F$ ). And this is informative.

\footnotetext{
18 I'm borrowing this helpful way of contrasting explanation and deliberation from Kearns and Star 2008:41.
} 
Draft. Please cite the official version which appears in the handbook.

But it's not clear that it's true, at least for reasons that are outweighed. Suppose Alvin ought not go to Rojo's, since he's running late for an appointment. Nonetheless, the fact that Rojo's has excellent coffee is a reason for Alvin to go to Rojo's. Does the fact that Rojo's has excellent coffee play a role in making it the case that Alvin ought not go to Rojo's? It's hard to see how it does. Wouldn't it still be the case that Alvin ought not go to Rojo's even if the coffee were mediocre? And, moreover, it's hard to see how this fact could play any role in making it the case that Alvin ought not go to Rojo's: it's pushing in the other direction - that is, toward the conclusion that Alvin ought to go to Rojo's. (Of course, what is true here is that this fact plays a role in making the balance of reasons what it is: were the coffee mediocre, then there would be one less reason to go to Rojo's. But saying that a reason can make a difference to the balance of reasons isn't saying anything particularly informative about what a reason is.) ${ }^{19}$

\section{§6. Reasons as Explanations of Value}

We could also develop the reasons-as-explanations strategy by replacing ought with good. On this view, reasons for $\mathcal{N}$ to $F$ are facts which explain why $\mathcal{N}$ 's $F$-ing would be good, or valuable, in some respect and to some degree. The following biconditional, if true, might allow for an analysis of reasons:

REV Necessarily, a fact $X$ is a reason for an agent $\mathcal{N}$ to $F$ if and only if $X$ explains why $\mathcal{N}$ 's $F$-ing would be good in some respect and to some degree. ${ }^{20}$

\footnotetext{
${ }^{19}$ For further discusssion of Broome's account see Schroeder 2007:35-36, Kearns and Star 2008, Raz 2011, and Brunero 2013.

20 The phrase "in some respect and to some degree" is taken from Raz 1999:23, who presents a view along these lines. See also Finlay 2006:7-8; 2012
} 
This seems to allow for an informative analysis of reasons, since we have some independent grasp on the concepts of explanation and value. And it can allow for the existence of outweighed reasons since something can be good in some respect and to some degree, but, at the same time, bad in another respect, and to a greater degree. Since the concept of goodness itself has a pro tanto character, it's an ideal tool for the reasons-as-explanations theorist to use to account for the pro tanto character of reasons.

One might challenge REV in the right-to-left direction. Not all explanations of why some action would be good in some respect and to some degree are reasons to perform that action. For one thing, I can explain what would be good about my performing a certain action that I can't now perform. But many philosophers have been persuaded by some "reasons-implies-can" principle, for many of the same reasons they have been persuaded by some "ought-implies-can" principle. (See Streumer 2007, and Streumer in this volume) So, although there's an explanation of what's valuable about performing the act, one wouldn't have a reason to perform that act, if one is unable to do so. To get around this worry, we would have to amend REV by adding "and $X$ is possible" to the right hand side of the biconditional. (And perhaps related amendments would be necessary to accommodate views which hold there to be a necessary connection between an agent's reasons and her motivations or possible deliberations. ${ }^{21}$ )

Additionally, many philosophers have denied the existence of pragmatic reasons for belief. (See Shah 2006. See also Reisner, in this volume.) These philosophers deny that reasons for belief are provided by anything other than the evidence for that belief. But they don't deny that when we point to the pragmatic benefits of a belief - say, by pointing out how believing in God makes you happy - we've explained what's valuable,

${ }^{21}$ See Williams 1981 for one such view. 
in some respect and to some degree, about having that belief. In this example, the belief in God is instrumentally valuable as a means to happiness, which has final value. But, according to evidentialists, that's no reason to believe in God.

One might also challenge REV in the left-to-right direction. Not all reasons for $\mathcal{N}$ to $F$ explain what's valuable about $\mathcal{N}$ 's $F$-ing. Remember that REV is a general thesis about reasons, and is meant to extend to attitudes as well as actions. ${ }^{22}$ But many philosophers are attracted to the idea that your reasons for attitudes are given by the ways in which the attitude would be fitting to its object: the respects in which something is admirable are reasons to admire it, the respects in which something is enviable are reasons to envy it, the respects in which something is detestable are reasons to detest it, the respects in which something is fearsome are reasons to fear it, the respects in which something you did is shameful are reasons for you to feel ashamed of it, and so on. Suppose I point to some respect in which Marvin is enviable: he has a fancy new car. This is a reason for you to envy Marvin. But does it explain why your envying Marvin would be good in some respect and to some degree? Well, it's not clear that your envying Marvin would be good in some respect and to some degree. That might depend on what the correct theory of value is - whether it's hedonism, or a desire-satisfaction theory, or some version of an objective list theory, or something else. Suppose you accept hedonism, and so you understand goodness in terms of the production of pleasure. Let's

\footnotetext{
${ }^{22}$ Stephen Finlay (2012) has developed a plausible and interesting way to understand reasons for belief in terms of goodness. Finlay defends an "end-relational" semantics for "good," according to which to say that something is good is to say that it's good for some particular end, where this end is either stated explicitly or made relevant by the context. And "good for an end" is itself understood naturalistically in terms of what raises the probability of the end. When it comes to (evidential, not pragmatic) reasons for belief, your reasons for believing that $\mathrm{P}$ are what explain why your believing $\mathrm{P}$ is epistemically good, where epistemic goodness, on the end-relational semantics, is understood in terms of the promotion of an end, namely, the end (often alleged to be a "constitutive aim" of belief) of believing $\mathrm{P}$ if and only if $\mathrm{P}$ is true. Consideration of Finlay's end-relational semantics here would take us too far afield.
} 
suppose, plausibly, that it's an empirical fact that your envying Marvin doesn't produce any pleasure. In that case, there would be nothing good about your envying him. So, if you don't give up your claim that Marvin's fancy new car is a reason to envy him, you must give up REV. That's already enough to show one way in which REV is controversial. Or suppose you accept some version of an objective list theory. Whether there is anything good about your envying Marvin depends upon whether your envying Marvin would promote any of the goods on your list. (Or perhaps your list itself includes, alongside happiness, knowledge, autonomy, etc., the having of attitudes appropriate to their objects - that is, the admiring of the admirable, the envying of the enviable, and so forth.) Again, we see that REV is controversial: by accepting both REV and that Marvin's fancy new car is a reason to envy Marvin, you are committed to thinking that your envying Marvin promotes or constitutes some good on the objective list, which may not be the case.

One could, of course, preserve REV by rejecting the claim that Marvin's fancy new car is a reason to envy him, or by adopting a theory of value which has it come out that your envying him would be good in some respect and to some degree. (How costly this objection to REV is depends upon how independently attractive the views incompatible with REV are.)

But there are other problems for REV's treatment of reasons for attitudes. ${ }^{23}$ Reasons for attitudes can be outweighed. For instance, one can have a reason to regret a decision, but weightier reasons not to regret a decision. Nancy can have a reason to regret marrying Oscar - perhaps she missed out on a romantic fling with Peter by doing

\footnotetext{
23 The following point parallels one made by Jonathan Way in an excellent discussion of the relationship between value and reasons for favoring in his paper, "Values and Reasons to Favor." to which my discussion here is very much indebted.
} 
so - but at the same time have many reasons not to regret marrying Oscar (they've had a long, fruitful partnership, characterized by enduring love, mutual respect, and mutual admiration). Nancy's reason to regret marrying Oscar (her missing out on a fling with Peter) is outweighed by the reasons not to regret marrying Oscar. But suppose REV is true. In that case, since Nancy's missing out on a fling with Peter is a reason to regret marrying Oscar, Nancy's missing out on a fling with Peter explains why her regretting marrying Oscar is good in some respect and to some degree. Since explanations are factive, her regretting marrying Oscar is good in some respect and to some degree. But it's hard to see how this could be so. What good would be promoted by her regretting a decision that resulted in an excellent marriage? It doesn't promote happiness, autonomy, knowledge, or anything like that. And it's hard to see how there would be final value in having such regret. Perhaps there's final value in regretting a decision that's regrettable (because, one might hold, there's final value in having attitudes fitting to their objects), but there's no final value in regretting a decision that there's merely a heavily outweighed reason to regret. (Similarly, perhaps there's final value in being frightened of something that is fearsome, but surely there's no final value in being frightened of something there's merely a lightweight reason to be frightened by, and lots of weighty reasons not to be frightened by.) In our example, it's hard to see how there's final value in Nancy's regretting her decision to marry Oscar. ${ }^{24}$ Since REV commits us to thinking that

\footnotetext{
${ }^{24}$ One might object: if we consider a variation on the example in which Nancy's marriage to Oscar is just as good, but there was no fling with Peter to miss out on, then wouldn't it be even worse for Nancy to regret her decision to marry Oscar? But how could that be, unless there was something good about her regretting her decision in the case where she does miss out on the fling with Peter? The objection misfires. It doesn't follow from B's being worse than A that there is something good about A. Nothing good comes from sticking your hand into a woodchipper. The fact that it would be worse to stick both hands in doesn't change that.
} 
Nancy's regretting her decision to marry Oscar is good in some respect and to some degree, we should reject REV.

In summary, it seems that not all explanations of why $\mathcal{N}$ 's $F$-ing would be good in some respect and to some degree are reasons for $\mathcal{N}$ to $F$, and not all reasons for $\mathcal{N}$ to $F$ are explanations of why $\mathcal{N}$ 's $F$-ing would be good in some respect and to some degree.

\section{§7. Conclusion}

I've here considered some ways one might to try to analyze reasons in terms of either evidence or explanations. I've highlighted some important advantages of reason-asevidence, but also presented some problems facing the view: the problem of counterevidential reasons, the problem of enablers, and the problem of non-explanatory evidence. I've also considered the reasons-as-explanations strategy, which can be developed in at least two ways, depending on whether we have "ought" or "good" in the explanandum. The former strategy has a difficulty when it comes to outweighed reasons, and it's not clear that Broome's disjunctive proposal adequately resolves this worry, and the latter strategy also runs into difficulty, since it seems there are counterexamples to REV in both directions. In conclusion, neither reasons-as-evidence nor reasons-asexplanations, at least in the formulations of those views considered here, have provided us with sufficient grounds for countering the skepticism of Scanlon and Parfit expressed in the quotations at the start of this paper. ${ }^{25}$

\footnotetext{
${ }^{25}$ For helpful written comments and discussions related to this paper, thanks to Peter A. Graham, Stephen Kearns, Daniel Star, Dana Tulodziecki, Jonathan Way, Eric Wiland, and to participants in the St. Louis Ethics Workshop and the Princeton Workshop in Normative Philosophy. I'm especially grateful to Daniel Star for many helpful conversations over the years regarding the topics covered in this paper.
} 


\section{References}

Achinstein, P., 2001, The Book of Evidence. Oxford: Oxford University Press.

Broome, J., 2004, "Reasons," in R. J. Wallace, M. Smith, S. Scheffler and P. Pettit (eds.), Reason and Value: Themes from the Moral Philosophy of Joseph Raz. Oxford: Oxford University Press, pp. 28-55.

-----., 2008, "Reply to Southwood, Kearns and Star, and Cullity," Ethics, 119: 96-108.

-----., 2013, Rationality Through Reasoning. Oxford: Wiley Blackwell.

Brunero, J., 2009, “Reasons and Evidence One Ought,” Ethics, 119: 538-545.

-----., 2013, “Reasons as Explanations,” Philosophical Studies, 165: 805-824.

Cullity, G.,"Weighing Reasons," in this volume.

Dancy, J., 2004, Ethics without Principles. Oxford: Oxford University Press.

Finlay, S., 2006, “The Reasons That Matter," Australasian Fournal of Philosophy, 84: 1-20.

-----., 2012, “Explaining Reasons,” Deutsche Fahrbuch for Philosophie, 4: 112-126.

Fletcher, G., 2013, “A Millean Objection to Reasons-as-Evidence,” Utilitas, 25: 417-420.

Kearns, S. and D. Star, 2008, "Reasons: Explanations or Evidence?,” Ethics, 119: 31-56.

-----., 2009, "Reasons as Evidence" in R. Shafer-Landau (ed.), Oxford Studies in Metaethics, Vol. 4. Oxford: Oxford University Press, pp. 215-242.

-----., 2011, "On good advice: a reply to McNaughton and Rawling," Analysis, 71: 506508.

-----., 2013, “Weighing Reasons,” Journal of Moral Philosophy, 10: 70-86.

-----., 2013b, "Reasons, Facts-About-Evidence, and Indirect Evidence," Analytic Philosophy, 54: 237-243.

McKeever, S. and M. Ridge, 2012, "Elusive Reasons," in R. Shafer-Landau (ed.), Oxford Studies in Metaethics, Vol. 7. Oxford: Oxford University Press, pp. 110-137.

McNaughton, D. and P. Rawling., 2011, "The Making/Evidential Reason Distinction," Analysis, 71: 100-102.

Parfit, D., 2011, On What Matters. Oxford: Oxford University Press. 
Raz, J., 1999, Engaging Reasons. Oxford: Oxford University Press.

-----., 201 1, From Normativity to Responsibility. Oxford: Oxford University Press.

Reisner, A., "Pragmatic Reasons for Belief," in this volume.

Scanlon, T. M., 1998, What We Owe to Each Other. Cambridge, MA: The Belknap Press of Harvard University Press.

Schroeder, M., 2007, Slaves of the Passions. Oxford: Oxford University Press.

-----., 2011, “Holism, Weight, and Undercutting," Nous, 45: 328-244.

Shah, N., 2006, “A New Argument for Evidentialism,” Philosophical Quarterly, 56: 481-498.

Streumer, B., 2007, “Reasons and Possibility,” Philosophical Studies, 136: 351-384.

-----., "Reasons and Ability," in this volume.

Thomson, J., 2008, Normativity. Chicago: Open Court.

Toulmin, S., 1950, An Examination of the Place of Reason in Ethics. Cambridge: Cambridge University Press.

Way, J., 2013, "Value and Reasons to Favour," in Russ Shafer-Landau (ed.), Oxford Studies in Metaethics, Vol. 8. Oxford: Oxford University Press, pp. 27-49.

Williams, B., 1981, "Internal and External Reasons," in Moral Luck. Cambridge: Cambridge University Press. 